\title{
Exploring Interconnections in SCM Body of Knowledge
}

\author{
José Crespo de Carvalho ${ }^{1}$, Cristina Machado Guimarães ${ }^{2} \&$ Ana Lúcia Martins ${ }^{1}$ \\ ${ }^{1}$ ISCTE-IUL, Lisbon University Institute, Portugal \\ ${ }^{2}$ INESC TEC (formerly INESC Porto) and Faculty of Engineering, University of Porto, Portugal \\ Correspondence: Cristina Machado Guimarães, INESC TEC (formerly INESC Porto) and Faculty of Engineering, \\ University of Porto, Portugal. E-mail: cristina.m.guimaraes@inescporto.pt
}

Received: December 28, 2013

doi:10.5430/jms.v5n1p39

\author{
Accepted: January 14, 2014 \\ Online Published: February 16, 2014 \\ URL: http://dx.doi.org/10.5430/jms.v5n1p39
}

\begin{abstract}
This paper aims at contributing to new insights and ideas in the area of Supply Chain Management.

Revisiting some theories and areas of knowledge is critical to generate different perspectives and ways of understanding supply chains. Accordingly, this paper reopens some areas of knowledge that have fed and are continuing to feed the area of SCM (Supply Chain Management) with new ideas and thoughts, in both theoretical and practical terms.

SCM approaches and practices are cross functional, organizational and inter-organizational centred areas of knowledge and, for these reasons, the authors have also made an effort to dedicate some parts of the paper to discuss and register some competitive advantages arising essentially from a pre-paradigmatic body of knowledge like SCM.
\end{abstract}

Keywords: supply chain management, competitive advantages, supply chain management strategic capacity

\section{Introduction}

The organization is a project with as many years as the humanity. It has gone through different forms and suffered several influences but no one can deny its importance to value creation and societies' health and development. Different streams of research of several areas of knowledge aim to observe and foresee the future of the organization in numerous dimensions and ways of thinking. The Supply Chain Management (SCM) area, its researchers and professionals should joint their efforts with the ones of other areas of knowledge as they have, at least, the intellectual obligation of participating in a permanent project that includes building and accompanying the outputs of this influence-construction-formation of the SCM body of knowledge. This paper is inserted in this intellectual effort of contributing to discuss and add other perspectives and understandings of the SCM area.

The methodology developed is totally interpretative. Interpretative and qualitative because authors aim to shake the minds (and "bodies") of other academics and professionals, within and outside the supply chain areas of knowledge. According to the authors perspective the need for shaking heads comes, more and more, from the (somehow) closed perspective of supply chain management/network management in the last years: frequently tangible, related with goods and having a goods dominant logic, being also static and locked when it is important to bring and incorporate new bodies of knowledge. However, authors firmly believe that supply chain management is an open area, vibrating in creating and incorporating knowledge and enlarging its frontiers. For example, it is very important to extend the area to workflow' supply chains and clients' supply chains. Workflow' and clients' supply chains because authors applied the reasoning, principles and ideas of logistics and supply chain management to courts of law (time, cost and quality of service), to consultants (work in, work out, eventually implementation), to fast food chains (clients in, meals, clients out), to retail banks (clients in, service, clients out) and to hospitals (patients in, attendance, patients out).

Being this context very rich and broad, the authors' minds converged their thoughts to the design of two main rows, aiming to focus their ideas and the paper focus: i) one that establishes the relations between other areas of knowledge and the body knowledge of SCM, searching mutual enrichment and the liaisons that the authors believe that should be considered when revisiting and foreseeing the SCM development; ii) another one that, with this body of knowledge and its influences, leads to the Supply Chain Management potential construction of competitive advantages, by organization or when inserting an organization in a supply or network chain of organizations. 
The propositions should be, theoretically, sustained by what authors considered to be their own ethos when regarding SCM, i.e., has it was stated, authors belong to a university/community with some tradition in the professional SCM world, are used to develop large scale consultancy projects in the area and to contribute to the scientific community. Obviously, a paper like this, with a proper nature, is very idiosyncratic and to some scale culturally, economically and politically dependent of geography and a way of doing and thinking SCM. Such concerns appear not as a strict way of justifying propositions but, instead, as a way of presenting to readers the importance authors are giving them when considering their own context, past, present and foreseen future:

Proposition 1 - The approaches visited, based in a SCM logic, suffer from a decisive influence of other areas of knowledge, not always considered in literature but that may justify it: the military area, the biological area, the economic area, the systems approach area, the psycho-sociological area, the quantitative methods area, the communication area, the creativity and the complexity thought areas and the strategic area.

Proposition 2 - The interconnection between different areas of knowledge that benefit and give origin to SCM should, on the one hand, contribute to the sustainability of this area (SCM) and, on the other hand, feed the continuous need of maintaining alive the SCM strategic capacity of the organization (meaning by strategic capacity what the strategic community understands by the ability to generate competitive advantages, both based on resources and/or competences; SCM strategic capacity meaning that SCM is able to generate its own strategic competitive advantages). Only with the creation of a proper and stable SCM body of knowledge one can foresee important and intrinsic competitive advantages emerging from this area and, thus, the future of the SCM logic and concept.

The development of these propositions using a conceptual, though and ethos centric and, in parallel, literature based approach will lead to a framework of thought aiming to contribute to the project of analyzing and foreseeing the future role of the organization. It is then considered that the future of the organization is critical to the future of the SCM concept, logic and knowledge. Thus, without a proper context in terms of organizational knowledge, way of construction and perspectives it is difficult to foresee the future of SCM for itself.

The topics suggested below are intended to contribute to the interpretation and dissect of the propositions and give birth to what are some of the authors' strong believes and corresponding contributions to the SCM development.

\section{Exploring Proposition 1 (on the areas that feed SCM perspective)}

The military area of knowledge brings with it thoughts in such dimensions as the critical components of cost and information in war and, additionally, the proper moment, the means (quantity and adequacy) in order to develop war (Sun Tzu, 1972) (Clausewitz, 1832). Relationships between the military knowledge and the knowledge developed by SCM approaches, particularly at the original level of the seven Rs (the right product, to the right client, in the right quantity, in the right condition, at the right place, at the right time and at the right cost) subjacent to the first steps of Logistics knowledge, should be made more evident.

Thus, history and facts have remarkably evidenced, not always explicitly but enough times, that military Logistics combines variables that, later on, have been used to the development of business Logistics, namely the seven Rs approach. Why not proposing, having those origins in mind, an approach that may combine and add both the military and the business dimensions, presenting (and recognizing) that approach more as a desirable state than a possible or an achievable result? SCM is, realistically, the happiest aggregation of a series of variables and dimensions which, even if they appear sometimes as being opposite, make an effort to be aligned with the 'rights' purposes ( 7 Rs) and envisaging time and cost reduction and quality of service enlargement.

From the 7 Rs proposal one may think that SCM should represent, always, a high service proposal simultaneously combined with a minimum cost. Observing this eventual proposal and the correspondent paradox (high service and low cost) one may be tempted to say that no company is able to achieve that position as an optimum and, quite sure, not for itself alone. Seen as a position, an absolute optimum, it is, in fact, impossible to sustain. Nevertheless, companies make their own balances between cost and service having trade-off management as the weapon to achieve well-adjusted cost-service positions and, then, properly answering their markets' needs.

The same problem occurs in wars. It is not possible to win all battles and all wars without losses and side or collateral effects. There are always tradeoffs and eventually balanced positions. Alone, for a country, a state or an army, it is also more difficult when trying to sustain a victory or managing all variables in an after war condition.

All added, organizations should try to, recurring to trade-off management, propose the better equilibrium between service and cost and, continuously, be open minded to new paradigms and frontiers, namely those that may be established throughout some degrees of collaboration, such as the ones proposed by Supply Chain Management, and not only instigating isolation and rivalry between then. This depends, of course, from market structures and from the 
positions organizations have in their own markets. Dimension and negotiation power will play a central role in collaboration achievements.

The area of the biological knowledge carries thoughts in such dimensions as the adaptability of species, thus organizations as different types of species, and also on the availability of resources in order to provide the survival of such species.

The idea of anticipating the future reality and, in consequence, the way one should develop, leads to the designing and/or purpose for foreseeing the evolution of species (Darwin, 1859), (Malthus, 1798), (Hannan \& Freeman, 1977), (Capra, 1983) and, in a more specific context, organizations; in consequence, it allows the search for planning and development of SCM.

It is a fact that a biological approach, like the species evolution, is somehow reactive to the environment if one only sees it from an historical perspective. However, each specie, even it is not in a formal or prescriptive/deliberate way, rather emergent, is also doing efforts to overcome the environment and to prevent difficulties in future adaptations (one would state, like Darwin (1859) that species are only reactive; but looking in another perspective, a set of responses, as a body of reactivity, shouldn't be considered, also, somehow a proactive approach? In organizations they sometimes are; in this context, responses to specific circumstances, namely when species fell pain, trouble or are fighting for surviving may be - wishful thinking (?) - seen as anticipating a dark future and, consequently, working to overcome that future, surviving and somehow thriving; organizations certainly are).

All added, if one complements military Logistics dimensions with business variables, namely when viewed throughout market eyes (seven Rs perspective, for instance), it is easy to foresee and conclude for the need of companies adjustment and adaptation, the evolution of species, in order to achieve degrees of collaboration that may answer to the necessary equilibrium between service at a minimal cost. Is this a frontier and works as a best case scenario? The only possible answer seems to be yes but only when the economy is more centered in knowledge and innovation factors than in power given by organizations' dimension. The original question, behind this one, is if the world is following the path of knowledge or if the world is also following the path of dimension, and consequently power, highly recommended for the classical industrial economy we may still live in.

If one wants to go deeper in this situation and searches answers for "in which world are we living in?", the power and dimension one or the knowledge and relational centered one, may find some answers in a relatively new approach, in historical terms, given by the topic of service dominant (S-D) logic, for instance. This logic has shown an incremental relevance in the literature and is contributing substantially to the volatility of companies' boundaries. In fact, it is very important, at the moment, to understand how all this new movements of S-D logic are interrelated (Pilkington \& Liston-Heyes, 1999) and form the overall snapshot of what is actually a changing and evolving structure of organizations and their reality. If organizations' boundaries are coming less evident nowadays, if one sees other logics arising that can contemplate deep interactions and dependencies between organizations, than one may think that the knowledge and relational worlds are coming more relevant than the classical power by dimension world.

The Service-Dominant philosophic stance is based around some foundational premises (Vargo \& Lusch, 2004; 2008a). The first of these foundational premises specifies that service (rather than goods) is the fundamental basis of exchange and all the providers are service providers (Vargo \& Lusch, 2004, 2006, 2008a, 2008b, 2008c, 2011). Integral to Vargo and Lusch (2004) S-D logic rationale is how "service" is defined as the application of competences (knowledge and skills) for the benefit of another entity (or the entity itself). Hence, the focal point of S-D logic changes, in terms of its resources, from operand to operant, showing that individuals exchange with the intent to acquire the benefits of applied specialised operant resources and, as such, exchange service for service, where tangible goods are seen as the distribution mechanism for service provision.

As it occurs in species, in biological terms, the survival and adaptability of species is mainly due to the collective desire/necessity of a series of individual beings that belong to a particular specie. This desire/necessity may be viewed in two perspectives: i) the perspective of species' openness to other species characteristics, acquiring competences that others already have or discovering and working new ones that may help them in building new capabilities (new capabilities may induce, subsequently, the development of new resources) and/or, in a parallel line of thought, ii) the perspective of a specie as an open system, adaptable to the circumstances of the surroundings. In either case the ones who may claim for a better living, in a world with reduced boundaries and increased relationships, are the ones with adaptable capabilities, hence the ones more opened to the external environment. This having in mind that there is, in parallel with the reactivity of the adaptation of species, a substantial work of proactivity, with emergent characteristics in a way to, even not consciousness, create better conditions for an organization to live and prepare the future. 
The economical area of knowledge carries the ideas of organizational arrangement (formation, development and structure, for instance) and establishes liaisons to the SCM knowledge mainly throughout the classical "make or buy" dilemma (Arrow, 1974), (Coase, 1937), (Penrose, 1959), (Williamson, 1985), (Simon, 1947), also explored in other areas of knowledge.

Moreover, the question may be raised and maintained to a higher economical level, i.e., to what point of economic benefit the classical organizations' arrangements may explain higher degrees of success, with strong levels of internalization, limited rationality and high heights of opportunism, namely when facing specificity of actives (Transaction Cost Analysis)? Or, else, if this classical approach may be complemented, enriched or even substituted, somehow, for a different organizational arrangement view, more based on networks, on reduced boundaries and on stronger relationships as opposed to strong forces, individualism and power? As an example of a relatively new logic or explanation of organizations one may see the ARA approach to networks - Actors, Relationships and Activities - as it is proposed by the Industrial Marketing and Purchasing Group (www.impgroup.org), namely by Gadde and Håkansson (2001) in its origins.

Additionally, one can also add here the S-D logic in order to reinforce the network theory, or a SCM theory with companies as service providers and service being defined, as it was already mentioned, as the application of competences (knowledge and skills) for the benefit of other entities (or the entity itself) - a SCM approach. In these circumstances, the focal point of the S-D logic may add new perspectives to a chain (or even a network) construction and management, i.e., in terms of its resources companies may migrate from the operand paradigm to the operant one, providing services and having goods as a mechanism for service exchange, always within a chain or a network of companies.

The systems thinking area of expertise brings on the logic of interdependent and dynamic knowledge in order to provide the connection between product flows, the ups and downs of inventory levels, the out of stock problems and the bullwhip effect in Supply Chains (Bertalanffy, 1968), (Boulding, 1956), (Forrester, 1958; 1961), (Sterman, 2000), (Checkland, 1981), (Le Moigne, 1977).

Additionally, what should one say if with more collaborative (with fewer boundaries) organizations in a supply chain it is expected to foresee higher levels of visibility, share of information and higher levels of service, within and between companies, and fewer levels of stockouts, low inventory levels, improved planning activities (including collaborative planning) and reduced bullwhip effects? What does this mean, also, in a S-D logic or within a paradigm approach that substitutes the focus on goods and stocks by the focus on service and opened chains and networks? Or, additionally, in a network environment with deep relationships for which actors and activities should be prepared? Systems thinking will be very useful in completing all this intellectual construction and thoughts and seeing the parts of the system, either being organizations, chains or networks, to achieve its teleological character: Value creation or co-creation with the participation of all the organizations evolved and their clients, being individuals or organizations, also evolved in this network or large service logic.

The psycho-sociological area of knowledge explores the organizational rationality (and irrationality) and its evolution and tries to explain how culture, values, practices and major rules in organizations will influence the course of action, and, consequently, the major or minor tendency to develop and give birth to SCM approaches (Weber, 1925), (Habermas, 1981), (Crozier, 1963), (Crozier \& Friedberg, 1977).

In fact, collaboration is a question of mindset, as it is searching for higher service levels (or service approaches) with minimal costs: the boundary of sustainable, or somehow successful, organizations: service at a low cost chimera? It is a mindset question, hence it can only be influenced by a proper culture, values and, again, collaborative practices and appropriate relationships.

The quantitative methods area of knowledge fundamentally appeals to the game theory and, particularly, to the collaborative or win:win games, essential when searching for internal integration between different silos or vertical/functional areas, and external integration when thinking organizations under a SCM approach (Shubik, 1959), (Morgenstern \& von Neuman, 1944), (Nash, 1950). Again, why not to ask for this important quantitative knowledge if and when applied to a logic of service between organizations and within a chain or a network of organizations?

Once more, SCM approach can pave the way to a new organizational paradigm, one that may be sustained by collaborative dimensions instead of only rivalry and force and power dimensions. Porter's (1980) five forces may be complemented, for instance, for the value net approach due to Bradenburger and Nalebuff co-opetition approach (1997).

The communication area of knowledge explores the way the organizational speech and the communication of the organization and its practices will lead the markets and generally all the stakeholders, along with the media or other 
channels of communication (below the line), to guarantee and be favorable to the organization practices and to emphasize the results achieved by the Supply Chain Management efforts (Maingueneau, 1991). One may add to this type of communication, conventionally more related to marketing but in a broader sense, another one that includes also the communication between and within organizations. Communication has been largely used to explain good organizations results or even drastic failures internally, with other companies and with markets. Communication, in SCM practices, influences the performance of the flows, both informational and physical (integrated in the overall service in an S-D logic), and the overall performance of the chain or network of organizations.

Consequently, communication and its effects may be used in a Supply Chain Management effort in order to clarify and reduce "gossip" within and between organizations and, additionally, to motivate and adjust them to a consensual and additional focus in final markets service needs (at a minimal cost). Communication is, as the common sense can tell everyone, critical under the perspective of service, service between companies and within a perspective of reduced boundaries and enriched environment of relationships.

The creativity and complexity thought areas are replacing the traditional dichotomy of the "or/or" thought by the inclusive "and/and" thought. This last way of thinking, in parallel with controlled and unstable conditions, or chaos conditions (frontier of maximum creativity conditions), may be essential for organizations that search to foresee the right product, at the right place, at the right time and at the right quantity, accompanied by a low cost approach, the frontier where sustainable organizations ought to be or wish to be. Paradoxically, this frontier is chimerical but having the same effect that the marshmallow on kids (kids fight for it!) when conducting companies: the more creative companies will find ways to get closer to the frontier and to reach good and sustainable results.

This impossible/paradoxical frontier (service at a minimum cost) is, in fact, a dynamic frontier that should not have a formal end (a continuous way that never ends). In this context, the appropriate state should be grounded in a type of thought obtained with creativity elements and, somehow, with a certain degree of complexity (Stacey, 1991), (Morin, 1982). After all, the purpose is to obtain service "and" low cost and not service "or" low cost.

Hence, one can see the inclusive way of thought, or the "and/and" approach, as the needed approach in order to explore the collaboration and creation of networks of organizations and a Supply Chain Management perspective.

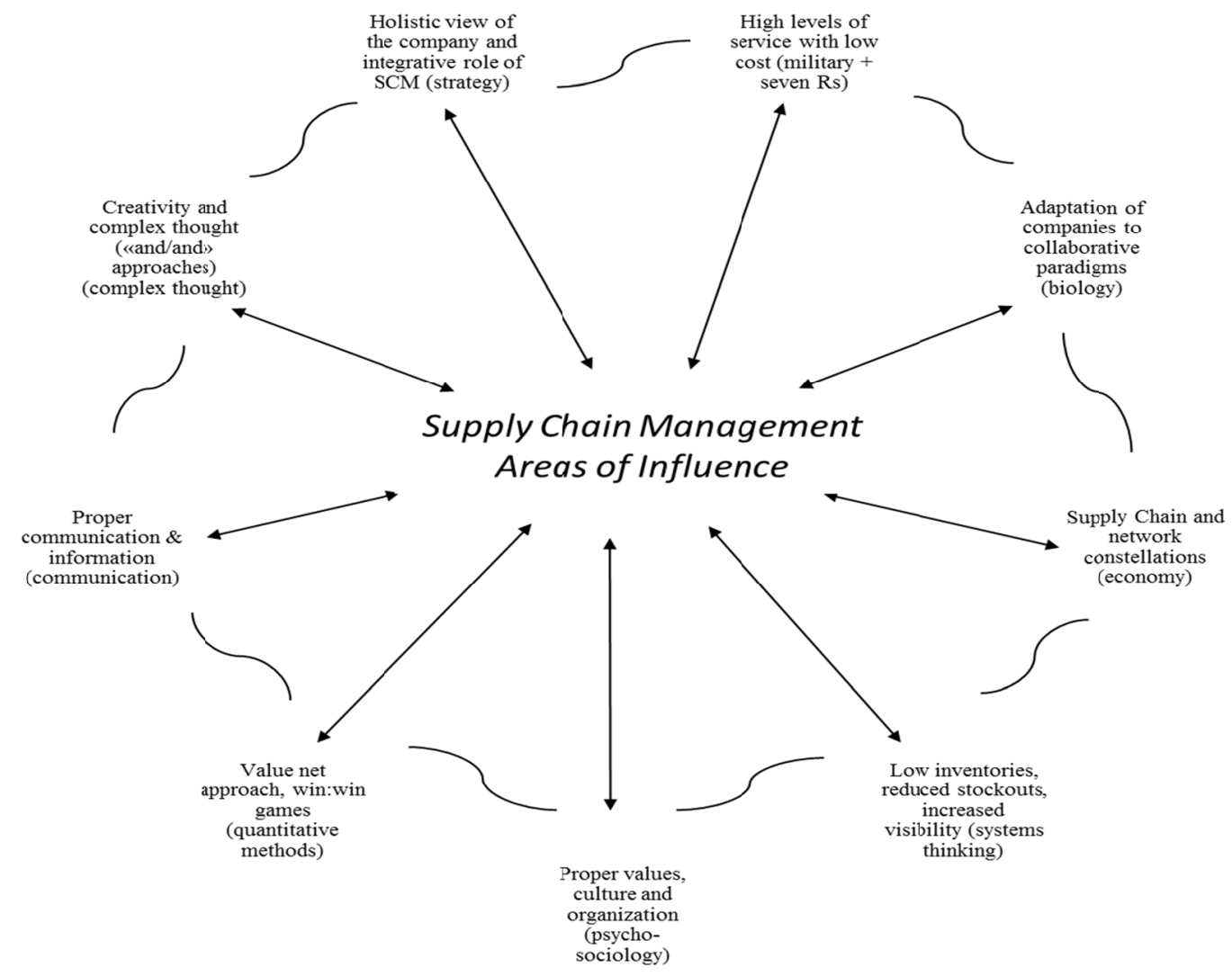

Figure 1. Supply chain management areas of influence (Result from Proposition 1) 
Finally, and without exhausting all the possible influences and areas of knowledge that contribute to the SCM logic, the strategic knowledge (Crespo de Carvalho \& Cruz Filipe, 2010) that presents the holistic, global and also pre-paradigmatic field of management (such as the SCM knowledge). One should try to look upon strategy as a holistic and supra-functional knowledge in a way that enables the balance between the different classical legitimacies or organizational paradigms, i.e., the shareholder legitimacy, the internal organization legitimacy and the market or client/transactional legitimacy. Complementarily, the SCM area may assume the role of integration between those different legitimacies or paradigms and its formal representations in organizations, bridging the gap between the so-called vertical or functional silos (Khun, 1983), (Popper, 1989), (Porter, 1980; 1985), (Mintzberg, Ahlstrand \& Lampel, 1998) (Crespo de Carvalho, J., 2010).

Essentially, SCM should be seen as a strategic weapon when companies are trying to collaborate and overpass the old competitive paradigms of isolation, power and forceful rivalry. Collaboration, once more, enables high service (and the paradigm of service supported by an S-D logic or a network approach) with a low cost perspective equilibrium (Or paradox? Or chimera?) under a trade-off management perspective. See the sum of influences explored in proposition 1 - Figure 1 - that may give the idea of an unending star/figure of influences, with no beginning and no end, but, instead, presented as a way of foreseeing what appears to be, in the authors' perspective, the complexity of the SCM Construction and the several influences that contribute to this construction.

\section{Exploring Proposition 2 (SCM as a competitive weapon)}

SCM knowledge, although an emergent one and built around other areas of knowledge, should create its own idiosyncrasies in order to be able, throughout them, to come to light as autonomous and capable to sustain competitive advantages. The type of arguments that are presented in SCM knowledge are hereby presented and shortly explored so that SCM knowledge appears as a creator and able to sustain competitive advantages for organizations (Mentzer, Min \& Bobbitt, 2004) (Bowersox \& Daugherty, 1995). The authors considered that exploring proposition 2 should be through small sub-propositions to cover the large one and to divide it buy subjects. Accordingly:

1) Intra-organizational collaboration/integration is vitally important to transform supply chains stakeholders goals' into competitive advantages;

The first step of everything in a world of relations and flows, in business as in life, begins within boundaries and with the need to abolish them. In order to reduce these boundaries one should work with his/her own self, where everything begins: self-awareness and self-management. The purpose is that each individual, knowing better the self, can evaluate and reassess necessities and priorities in order to perform better in terms of relationships. Additionally, one should be able to enrich his/her self and apply personal relational managed characteristics to the milieu of the organization and throughout organizations in order to obtain better overall performance, having always in mind proper idiosyncrasies, nature, personality and contribution to collective cultures. SCM it is not different. The first steps to a SCM approach should begin by destroying internal walls, vertical silos and to give birth to a horizontal and flat organization, focused and driven by the market.

2) Inter-organizational collaboration/integration is a way to create joint competitive advantages to the organizations participating in supply chains;

Once the internal steps have been taken, once the self is assessed and reassessed, known and properly managed, as the inside walls of the company, the trip should start to overcome organizations borders and look outside their boundaries, to their possible collaborative organizations (probably in a co-opetition approach) in the network of supply chains. S-D logic and network approaches should provide here new ways of thinking and analyzing reality and, in accordance, contributing to build an entire new world of relationships and an open interconnected "ecosystem" of organizations: the way organizations should create shared competitive advantages.

3) Effectiveness in supply chains may pave the way to provide availability/service, in a broader sense, or the right product, at the right place, at the right time and at the right quantity, in a straight sense, at the lowest cost, being, somehow, an approach to differentiation or, better, to obtain a joint world of low cost and differentiation (sometimes being a blue ocean as is it called by Kim and Maubourgne, (2005)).

Doing the right things is the previous step in relation to doing the things right. Of course this statement could generate lots of controversy because maybe no one knows which one will come first: logically one should think in what to do and only after in doing it properly. Reality shows that sometimes this reasoning is not as simple as that and that there are, sometimes, parallel rows between effectiveness and efficiency. The intention is, somehow, to add service to low cost perspectives and, thus, being in a paradoxical world or a 
chimerical one, as it was already mentioned in this article. Maybe the overall purpose of SCM, as it was recognized, is also chimerical. This chimera is, somehow, the unique way supply chain managers have found to create challenges or to present the "carrot" to audacious organizations. And only creative, audacious and maybe complex (in a sense of controlled chaos) organizations could find equilibriums between cost and service, or foresee high service levels at low cost levels.

4) Processes efficiency in the supply chain is a way of reducing costs;

Doing things right is, with some controversy, the second step to cost reduction in order to obtain the complex SCM approach and being capable of high service standards (and service logics) at low cost levels. Looking to this proposition it should be concluded that service becomes first and cost reduction is the following row. As it was stated in the previous sub-proposition and its discussion maybe there are some parallel rows between effectiveness and efficiency.

5) Gains in productivity can be achieved in supply chains throughout cost reduction in inputs when considering the results obtained with the enlargement of the client service package throughout the effectiveness obtained with the outputs;

Productivity gains are intrinsically related with doing the things right and doing the right things simultaneously. Proper effectiveness with appropriate efficiency means high levels of productivity. High levels of productivity are important to better serve clients and/or to have high service standards (and service logics between companies) with low cost levels and to launch the challenge and the "carrot" to pursue.

6) Competitive advantages to organizations that participate in supply chains can be obtained with a good articulation and balance of the "make or buy" dilemma;

If properly managed, the "make or buy" dilemma is a real weapon to gain and enlarge collaborative competitive advantages and not only individual, isolated and forceful competitive advantages. An organization focusing on its core business is able to better "buy" to other organizations and build proper supply or network of organizations contributing to an open ecosystem of systems or organizations.

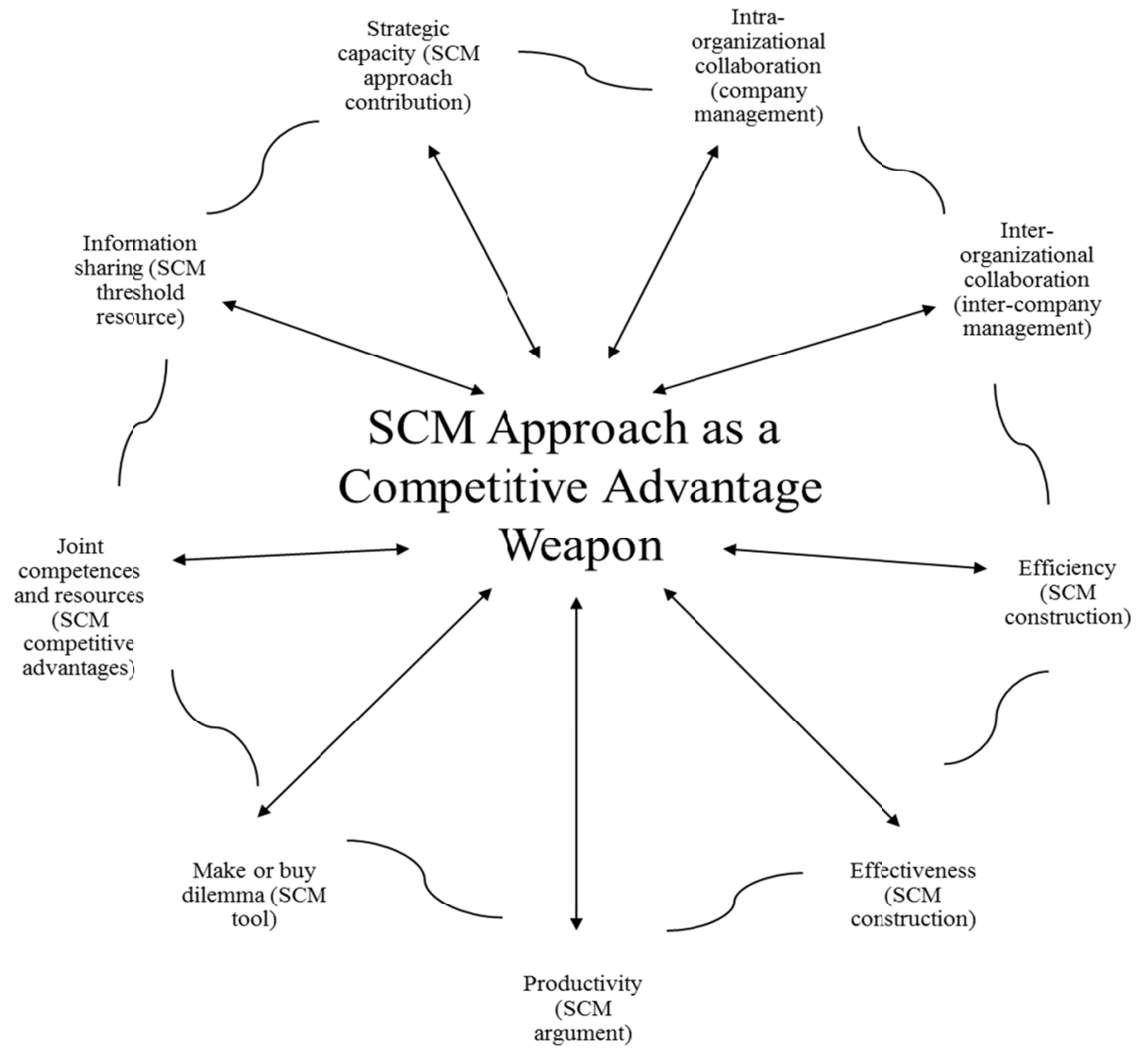

Figure 2. SCM approach as a competitive advantage weapon (Result from Proposition 2) 
7) Competitive advantages created for supply chain participants can be achieved when rightly combining supply chain competences and resources;

Collaborative competitive advantages are the resultant consequences of core competences with threshold resources. In this circumstance, however, or under a SCM approach, threshold resources and core competences may be obtained by the proper combination of shared resources and common competences to the organizations participating in supply chains or networks of organizations.

Under the perspective of a S-D logic, service is defined as the application of competences (knowledge and skills) for the benefit of another entity (or the entity itself). Services are explored and so competences are also explored. Or vice-versa. Additionally, the focal point of S-D logic changed, in terms of companies' resources, from operand to operant. And within an operant logic, competences are clearly different from the competences used and developed to manage and exchange goods between companies. The same reasoning should be reached with a proper network approach, i.e., with a network approach adjusted to what may come with the reality of supply chains: proper and prepared actors (and/or organizations), convenient/adjusted activities and enriching relationships (Gadde \& Håkansson, 2001).

8) Competitive advantages for supply chain participants can be achieved using properly the information that derives from the order cycle process or other supply chain origins, like service contracts, service specifications, among others;

Information is a key source and resource (threshold resource) that should flow within and between companies trying to develop a supply chain approach. Information sharing, as well as proper and clear communication, are SCM enablers and, simultaneously, key drivers for enlarging the collaboration mindset, namely stimulating confidence between organizations. Under a service perspective and when organizations change from an operand to operant logic competences rise to a level of criticality still not faced in organizations. With the rise of competences, information will rise, also, to levels with unprecedented importance.

9) Competitive advantages obtained throughout adequate service and general quality provided to customers can be achieved with the development of strategic capacity in organizations, meaning with this the right and unique combination of the appropriate supply chain resources and competences.

In sum, and after all, threshold common or shared resources, like pipeline or network information, and common core competences, the ones needed for an overall service logic, will emerge in supply chain integrated companies when one is prepared to develop collaborative strategic capacities within and between each organization (see Figure 2).

\section{Final Discussion}

The future of SCM will be a consequence both from the development of knowledge areas that influence the SCM knowledge creation - as have been shortly explored in this paper - and, in parallel, from new chapters and idiosyncrasies (specific proposals of arrangement within and between organizations in order to obtain service at a low cost level, integrating silos and departments internally and organizations and their value chains externally, in order to pursue gains in effectiveness, efficiency, productivity and overall customer service) possible to obtain within the body of knowledge created around the concept and applications of SCM, namely the service dominant logic and the network approach, among others.

The steps forward in the creation of new bodies of knowledge in the Supply Chain area may be very important and influential to the way one sees, analyses and manages organizations. Notwithstanding, it will be difficult to see and expect advances that may transform an "area of areas" or a "body of bodies" of knowledge in a specific, bounded and somehow with several stabilized components, to be clear, in a paradigmatic discipline in terms of knowledge. The advances of other areas of knowledge will always amplify the need for change and enrich the Supply Chain Management area and one of its main specificities, i.e., its pre-paradigmatic character.

\section{References}

Arrow, K. (1974). The Limits of Organization. Fels Lectures in Public Policy Series. ISBN: 0-393-09323-9.

Bertalanffy, L.V. (1968). General Systems Theory. Penguin Books. French Translation, Dunod, Paris.

Boulding, K. E. (1956). General Systems Theory - the skeleton of a science. Management Science, 2(3), 197-208. http://dx.doi.org/10.1287/mnsc.2.3.197 
Bowerson, D. J., \& Daugherty, P.J. (1995). Logistics Paradigms: The Impact of Information Technology. Journal of Business Logistics, 16(1), 65-80.

Brandenburger, A. M., \& Nalebuff, B. J. (1997). Co-Opetition: A Revolution Mindset That Combines Competition and Cooperation: The Game Theory Strategy That's Changing the Game of Business. Broadway Business, USA.

Capra, F. (1983). Le Temps du Changement. Éd. Du Rocher. Monaco.

Chan Kim, W., \& Mauborgne, R. (2005). Blue Ocean Strategy. Harvard University Press.

Checkland, P. (1981). Systems Thinking, Systems Practice. John Wiley and Sons, Ldt.

Clausewitz, C. (1832). Vom Kriege. Dümmlers Verlag. Berlin.

Coase, R. (1937). The Nature of the Firm. Economica, 4(169), 386-405. http://dx.doi.org/10.1111/j.1468-0335.1937.tb00002.x

Crespo de Carvalho, J. (2010). Logística e Gestão da Cadeia de Abastecimento. Edições Sílabo. Lisbon.

Crespo de Carvalho, J., \& Cruz Filipe, J. (2010). Manual de Estratégia. Edições Sílabo. Lisbon.

Croizer, M. (1963). Le Phénomène Bureaucratique. Éditions du Seuil, Paris.

Croizer, M., \& Friedberg, E. (1977). L'Acteur et le Système. Éditions du Seuil. Paris.

Forrester, J. W. (1958). Industrial Dynamics: A Major Breakthrough for Decision Makers. Harvard Business Review, $36(4), 37-66$.

Forrester, J. W. (1961). Industrial Dynamics. The MIT Press, Cambridge. MA.

Gadde, L.E., \& Håkansson, H. (2001). Supply Network Strategies. John Wiley and Sons Ltd.. UK.

Habermas, J. (1981). Theorie des Kommunikativen Handelns (Bd.1: Handlungsrationalität und gesellschaftliche Rationalisierung; Bd. 2: Zur Kritik der funktionalistischen Vernunft). Frankfurt a Main.

Hannan, M., \& Freeman, J. (1977). The Population Ecology of Organizations. American Journal of Sociology, 82(5), 929-964. http://dx.doi.org/10.1086/226424

Kuhn, T. S. (1983). La Structure des Révolutions Scientifiques. Éditions Flammarion. Paris.

Le Moigne, J.L. (1977). La Théorie du Système Général: Théorie de la Modélisation. Presses Universitaires de France. Paris.

Mainggueneau. (1991). L'Analyse du Discours. Éd. Hachette. Paris.

Malthus, T. (1798). An Essay of the Principle of Population, as it affects the future improvement of society with remarks on the speculations of Mr. Godwin, M. Condorcet, and other writers. J. Johnson, in Paul's Church-yard. London.

Mathé, J.C., \& Rivet, A. (1992). Les Doctrines Stratégiques d'Entreprise. Les Éditions D’Organisation Université. Paris.

Mentzer, J. T., Min, S., \& Bobbit, L. M. (2004). Toward a unified theory of Logistics. International Journal of Physical Distribution \& Logistics Management, 34(8), 606-627. http://dx.doi.org/10.1108/09600030410557758

Mintzberg, H., Ahlstrand, B., \& Lampel, J. (1998). Strategy Safari. Prentice Hall. London.

Morin, E. (1982-2004). La Méthode. 6 Vols. Éditions Seuil. Paris.

Nash, J. (1950). Equilibrium Points in N-Person Games. Proceedings of NAS- National Academy of Sciences, 36, 48-49. http://dx.doi.org/10.1073/pnas.36.1.48

Penrose, E. (1959). The Theory of the Growth of the Firm. Oxford University Press. Oxford.

Pilkington, A., \& Listo-Heyes, C. (1999). Is production and operations management a discipline? A citation/co-citation study. International Journal of Operations and Production Management, 19(1), 7-20. http://dx.doi.org/10.1108/01443579910244188

Popper, K. (1989). La Quête Inachevée. Ed. Press-Pocket.

Porter, M. (1980). Competitive Strategy. The Free Press. New York.

Porter, M. (1985). Competitive Advantage. The Free Press. New York.

Shubik, M. (1959). Strategy and Market Structure. John Wiley. New York. 
Simon, H. (1947). Administrative Behaviour. The Free Press. New York.

Stacey, R. (1991). Chaos Frontier: Creative Strategic Control for Business. Butterworth-Heinemmann. Oxford.

Sterman, J. D. (2000). Business Dynamics: Systems Thinking and Modeling for a Complex World. Irwin McGraw-Hill. New York.

Sun Tzu. (1972). The Art of War. Translated and with an introduction by Samuel B. Griffith. Penguin Books. London.

Vargo, S. L., \& Lusch, R. F. (2004). Evolving to a new dominant logic for marketing. Journal of Marketing, 68(1), 1-17. http://dx.doi.org/10.1509/jmkg.68.1.1.24036

Vargo, S. L., \& Lusch, R. F. (2006). Service-dominant logic: What it is, what it is not, what it might be. In R. F. Lusch and Vargo S. L. (Eds.), The service-dominant logic of marketing: Dialog, debate, and directions. New York. NY: M. E. Shape.

Vargo, S. L., \& Lusch, R. F. (2008a). From goods to service(s): Divergences and convergences of logics. Industrial Marketing Management, 37(3), 254-259. http://dx.doi.org/10.1016/j.indmarman.2007.07.004

Vargo, S. L., \& Lusch, R. F. (2008b). Why “service"?. Journal of the Academy of Marketing Science, 36(1), 25-38. http://dx.doi.org/10.1007/s11747-007-0068-7

Vargo, S. L., \& Lusch, R. F. (2008c). Service-dominant logic: Continuing the evolution. Journal of the Academy of Marketing Science, 36(1), 1-10. http://dx.doi.org/10.1007/s11747-007-0069-6

Vargo, S. L., \& Lusch, R. F. (2011). It's all B2B... and beyond: Toward a systems perspective of the market. Industrial Marketing Management, 40(2), 181-187. http://dx.doi.org/10.1016/j.indmarman.2010.06.026

Von Neuman, J., \& Morgenstern, O. (1944). Theory of Games and Economic Behavior. Princeton University Press, New Jersey.

Weber, M. (1925). Wirtschaft und Gesellschaft, Tubingen.

Williamson, O. E. (1985). The Economic Institution of Capitalism. The Free Press, New York. Retrieved from www.impgroup.org 